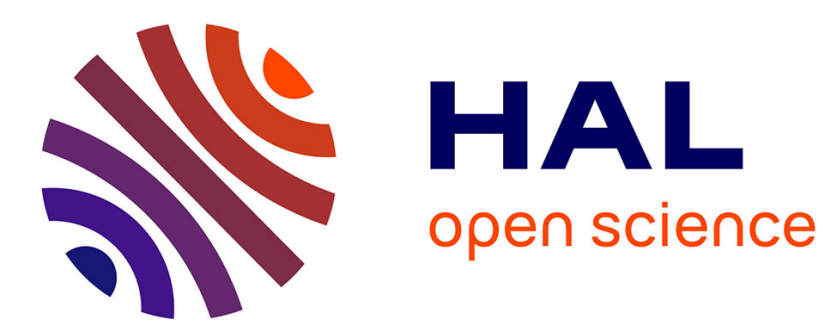

\title{
OPTICAL PROPERTIES OF ORDERED AND DISORDERED Au-Cu ALLOYS
}

J. Rivory

\section{To cite this version:}

J. Rivory. OPTICAL PROPERTIES OF ORDERED AND DISORDERED Au-Cu ALLOYS. Journal de Physique Colloques, 1974, 35 (C4), pp.C4-51-C4-56. 10.1051/jphyscol:1974407 . jpa-00215598

\section{HAL Id: jpa-00215598 https://hal.science/jpa-00215598}

Submitted on 1 Jan 1974

HAL is a multi-disciplinary open access archive for the deposit and dissemination of scientific research documents, whether they are published or not. The documents may come from teaching and research institutions in France or abroad, or from public or private research centers.
L'archive ouverte pluridisciplinaire HAL, est destinée au dépôt et à la diffusion de documents scientifiques de niveau recherche, publiés ou non, émanant des établissements d'enseignement et de recherche français ou étrangers, des laboratoires publics ou privés. 


\title{
OPTICAL PROPERTIES OF ORDERED AND DISORDERED Au-Cu ALLOYS
}

\author{
J. RIVORY \\ Laboratoire d'Optique des Solides, Université Paris VI, \\ 4, place Jussieu, 75230 Paris Cedex 05, France
}

\begin{abstract}
Résumé. - La constante diélectrique complexe d'alliages or-cuivre est déterminée par mesure de la transmission et de la réflexion de couches minces entre 0,5 et $6,2 \mathrm{eV}$. Nous étudions les alliages désordonnés en toute concentration, ainsi que les alliages ordonnés au voisinage des surstructures $\mathrm{AuCu}$ et $\mathrm{AuCu}_{3}$. La structure des échantillons est contrôlée par diffraction électronique. Nous avons étudié particulièrement la variation de la limite d'absorption interbande en fonction de la concentration et nous observons une variation non linéaire. Nous étudions l'influence de l'ordre pour les deux surstructures $\mathrm{AuCu}$ et $\mathrm{AuCu}_{3}$.
\end{abstract}

\begin{abstract}
The complex dielectric constant between 0.5 and $6.2 \mathrm{eV}$ of Au-Cu alloys has been determined from reflectance and transmittance measurements on thin films. Disordered alloys in the whole composition range as well as ordered alloys for compositions in the vicinity of the $\mathrm{AuCu}$ and $\mathrm{AuCu}_{3}$ superlattices are considered. The alloy structures are controled by electron diffraction. Special attention is paid to the interband transition absorption as a function of composition. A non-linear variation of the interband transition onset is observed. The influence of ordering is investigated for both $\mathrm{AuCu}$ and $\mathrm{AuCu}_{3}$ superlattices.
\end{abstract}

1. Introduction. - The samples under investigation are semi-transparent films of $\mathrm{Au}-\mathrm{Cu}$ alloys deposited on amorphous silica substrates by simultaneous evaporation of the two constituents from a single tungsten boat, in a vacuum of $10^{-7}$ torr.

The alloy concentration is obtained from the value of the crystallographic parameter deduced from the angular position of the (111) X-ray diffraction peak; it is also determined, for verification, by microanalysis using an electron microprobe [1]. The film thickness is given by a method based on X-ray interferences [2] with $1 \%$ accuracy.

As shown by the diagram corresponding to the Au-Cu system [3], solid solutions exist in the whole composition range. These alloys can exist in a disordered phase. For $\mathrm{Cu}$ atomic concentrations in the vicinity of $x=0.75$ and $x=0.50$, ordered phases corresponding to the superlattices $\mathrm{AuCu}_{3}$ and $\mathrm{AuCu}$ can be formed. In these cases, the ordered phase is the phase stable at low temperature. All our samples are examined by electron microscopy and electron diffraction in order to identify their crystallographic structure.

The complex dielectric constant of the alloy films is deduced from measurements of their reflectance and transmittance in nearly normal incidence, between 0.5 and $6.2 \mathrm{eV}$.

2. Disordered alloys. - In the concentration ranges where ordered phases can exist, the disordered phase can be obtained in two different ways :
- As the film deposition indeed consists in quenching the vapour, the as-deposited alloys are disordered, these phases being metastable at room temperature. However, there is some evidence of short range order [4], as shown by the bump located between the theoretical positions of the (100) and (110) superlattice peak in the densitometer analysis of the diffraction diagram (Fig. 1). The as-deposited films are made of very small crystallites $(100 \AA)$.

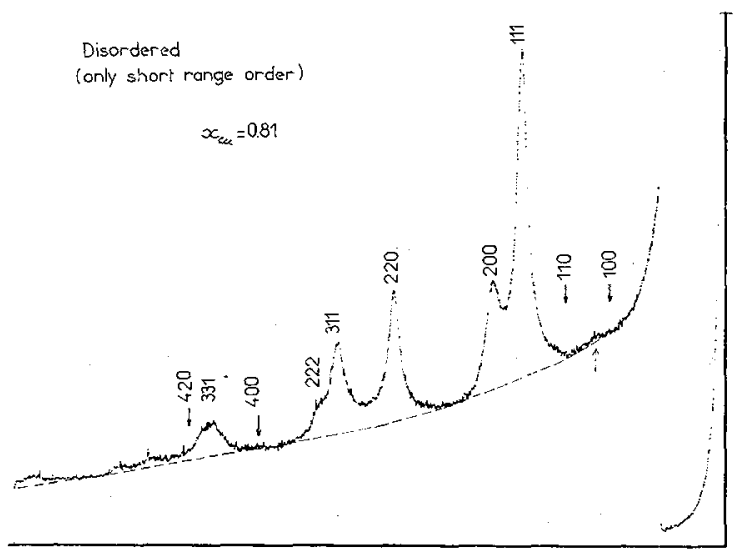

FIG. 1. - Microdensitometer analysis of an electron diffraction diagram of an alloy film with $X_{\mathrm{Cu}}=0.81$ in disordered state, presenting some short range order (see the arrow).

- If the as-deposited film is heated above room temperature, the alloy becomes ordered and at the 
same time the film recrystallizes. If the temperature is raised above the order-disorder transformation temperature (depending on the composition), the disordered phase, stable at high temperature, is obtained. This phase can in principle be preserved at room temperature in metastable state if the film is quenched in a suitable way. The crystallite size is then comparable ( $3000 \AA)$ in the annealed ordered alloy films and in the annealed and quenched disordered ones. However, obtaining completely disordered samples by this method proved to be very difficult, the result depending sensitively on the quenching temperature and the quenching rate.

2.1 INTRABAND TRANSITIONS. - For wavelengths greater than the interband transition onset, the complex dielectric constant $\varepsilon=\varepsilon_{1}-i \varepsilon_{2}$ can be written, according to the Drude theory :

$$
\begin{aligned}
& \varepsilon_{1}=P-\frac{\lambda^{2}}{\lambda_{0}^{2}\left(1+\frac{\lambda^{2}}{\lambda_{\tau}^{2}}\right)} \\
& \varepsilon_{2}=\frac{\lambda^{3}}{\lambda_{0}^{2} \lambda_{\tau}\left(1+\frac{\lambda^{2}}{\lambda_{\tau}^{2}}\right)}
\end{aligned}
$$

where $\lambda_{\tau}=2 \pi c \tau, \tau$ being the optical relaxation time of the conduction electrons

$$
\lambda_{0}^{-2}=\frac{N e^{2}}{\pi m_{0} c^{2}}=\frac{N_{\text {eff }} \times e^{2}}{\pi m c^{2}},
$$

$m_{0}$ being their optical mass or $N_{\text {eff }}$ their effective number per volume unit; $P$ accounts for the core polarization and the interband transition contribution.

In order to fit our experimental results to such formulas, it was necessary to add to the Drude expression for $\varepsilon_{2}$ a term of the form $A \lambda, A$ being a cons$\operatorname{tant}$ [5].

An equivalent treatment is to introduce a relaxation time $\tau$ varying with frequency according to [6] :

$$
\frac{1}{\tau}=\frac{1}{\tau_{0}}+b \omega^{2}
$$

$\tau_{0}$ being the extrapoled value at zero-frequency, and $b$ being a constant.

Figure 2 shows the variation with atomic $\mathrm{Cu}$ concentration $X_{\mathrm{Cu}}$ of the reciprocal zero-frequency relaxation time $\tau_{0}^{-1}$. A Nordheim-type variation, similar to the variation of the electrical resistivity [7], is obtained ; the values of $\tau_{0}^{-1}$ are comprised between 1 and $3.5 \times 10^{14} \mathrm{~s}^{-1}$.

The values of the optical mass for the different alloys are located in the vicinity of and below the straight line joining the pure metal values, as shown by figure 3 . The $m_{0}$ variation with concentration does not seem to be linear but the negative deviation remains small. The accuracy of the $m_{0}$ determination is not sufficient to infer the exact variation law.

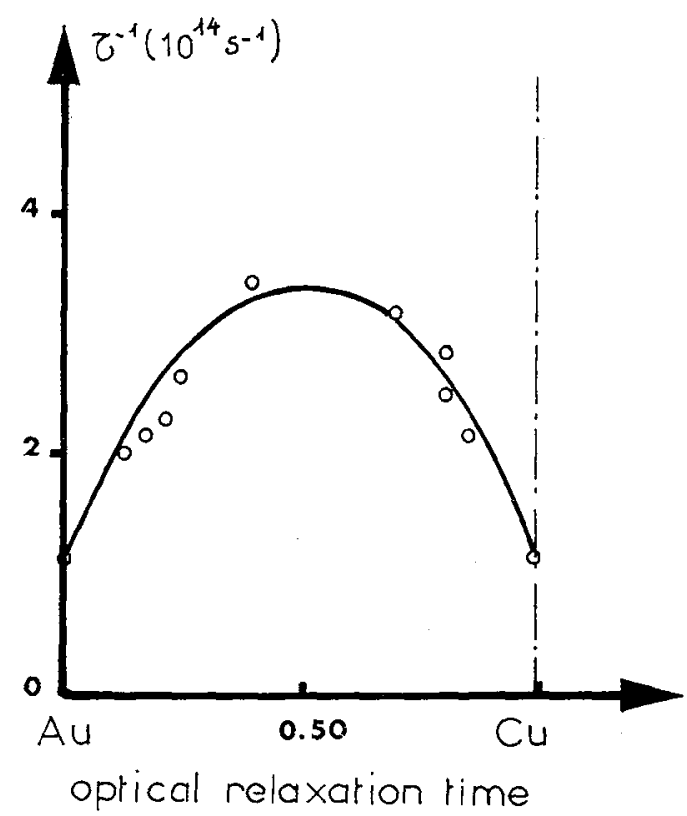

Frg. 2. - Variation with $\mathrm{Cu}$ concentration $X_{\mathrm{Cu}}$ of the reciprocal optical relaxation time $\tau_{0}^{-1}$ for disordered $\mathrm{Au}-\mathrm{Cu}$ alloys.

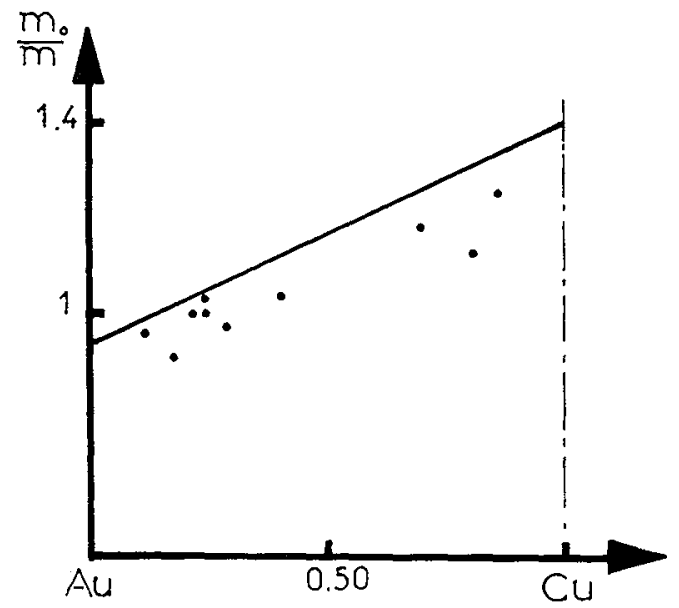

\section{optical mass}

Frg. 3. - Variation with $X_{\mathrm{Cu}}$ of the optical mass $m_{0}$ for disordered Au-Cu alloys.

2.2 INTERBAND TRANSITIONS: - Figure 4 shows the interband transition contribution to $\varepsilon_{2}, \varepsilon_{2}^{\text {inter }}$, versus energy for disordered alloys with different compositions as well as for pure $\mathrm{Au}$ and pure $\mathrm{Cu}$.

For Au-rich alloys, the curves are very similar to the curve relative to pure Au. The absorption edge retains approximately the same shape but the first maximum moves towards lower energies when $X_{\mathrm{Cu}}$ increases. On the contrary, the second maximum (located for pure $\mathrm{Au}$ at 3.9-4 eV) remains remarkably unchanged up to $X_{\mathrm{Cu}}$ as high as 0.40 . The same behaviour has been observed by $P$. $O$. Nilsson et al. [8]. 


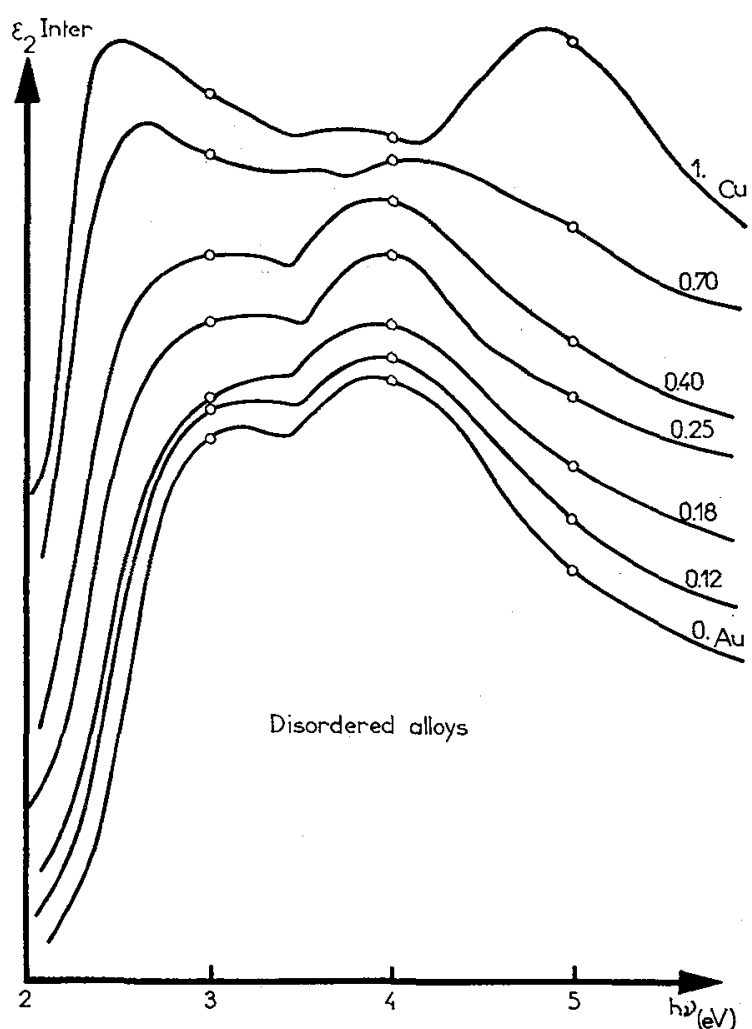

FIG. 4. - Contribution $\varepsilon_{2}^{\text {inter }}$ of interband transitions to the imaginary part of the dielectric constant as a function of energy for pure $\mathrm{Au}$, pure $\mathrm{Cu}$ and disordered $\mathrm{Au}-\mathrm{Cu}$ alloys with different compositions.

The curves corresponding to $\mathrm{Cu}$-rich alloys present, like the pure $\mathrm{Cu}$ one, a steep absorption edge, and the first maximum (located for pure $\mathrm{Cu}$ at $2.5 \mathrm{eV}$ ) is only slightly shifted towards higher energies when $\mathrm{Au}$ is added to $\mathrm{Cu}$. On the contrary, the second peak visible for pure $\mathrm{Cu}$ at about $4.9 \mathrm{eV}$ seems to be washed out very rapidly on alloying; it cannot be seen for the alloy with $X_{\mathrm{Cu}}=0.70$, however there is a faint maximum in this case around $4.1 \mathrm{eV}$. From these results, it can be inferred that the origin of the high-energy maximum in the $\varepsilon_{2}^{\text {inter }}$ spectrum is different in pure $\mathrm{Cu}$ and in pure $\mathrm{Au}$. While in $\mathrm{Cu}$ this maximum seems to be due, at least partly, to transitions between conduction bands, quite sensitive to alloying, in $\mathrm{Au}$ it has to be attributed essentially to transitions from the lower d-bands to the Fermi level, as proposed according to recent band calculations [9].

From the optical results, it was tried to deduce the variation with composition of the interband transition onset $\omega_{0}$. The method of determination of $\omega_{0}$ proposed in the case of pure Au [5] can be applied to the Au-rich alloys since the quantity $J(\omega)=\varepsilon_{2}^{\text {inter }}(\omega) \times \omega^{2}$, which is proportional - if constant matrix elements are assumed - to the joint density of states, still presents in the vicinity of the interband absorption onset the simple form :

$$
J(\omega) \propto\left(\omega-\omega_{0}\right)^{1 / 2}
$$

$\omega_{0}$ is then by definition the value of the onset $\left(\omega_{0}=2.45 \mathrm{eV}\right.$ for pure $\left.\mathrm{Au}\right)$. But for pure $\mathrm{Cu}$ and $\mathrm{Cu}$-rich alloys, this empirical variation is not satisfied, therefore the same method cannot be applied over the whole composition range. It was then decided to define, for all alloys as well as for pure $\mathrm{Au}$ and pure $\mathrm{Cu}$, the interband transition onset $\omega_{0}$ as the energy corresponding to the point at halfheight of the first maximum in $\varepsilon_{2}^{\text {inter }}$. This gives for example for pure $\mathrm{Au}, \omega_{0}=2.50 \mathrm{eV}$ (instead of $2.45 \mathrm{eV}$ by the method described above) and for pure $\mathrm{Cu}, \omega_{0}=2.18 \mathrm{eV}$ (instead of $2.08 \mathrm{eV}$ by linear extrapolation to zero of $J(\omega))$.

With both definitions, the variation of $\omega_{0}$ with $X_{\mathrm{Cu}}$ is qualitatively the same : it is not linear, the deviation being negative with respect to the straight line joining the pure metal values (Fig. 5). This means that $\omega_{0}$ decreases rapidly when $\mathrm{Cu}$ is added to $\mathrm{Au}$, while $\omega_{0}$ is practically insensitive to the addition of $\mathrm{Au}$ to $\mathrm{Cu}$, and then increases very slowly (observed also by Nilsson).

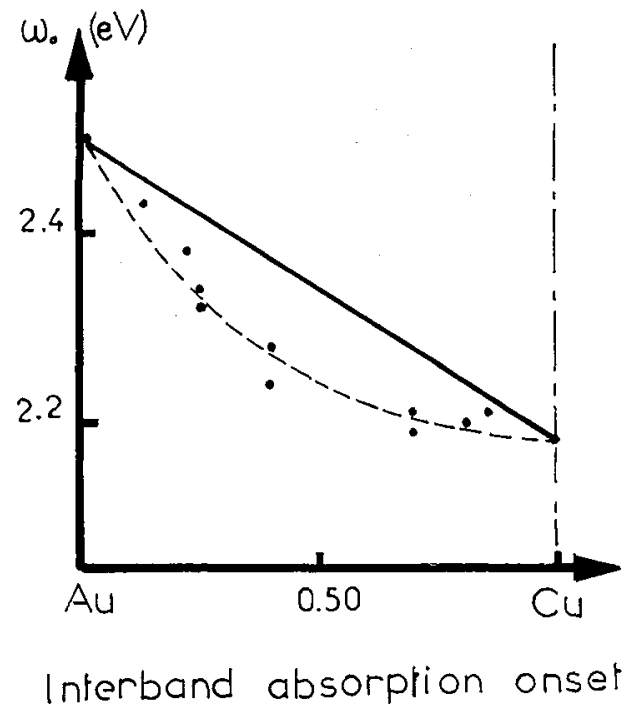

FIG. 5. - Variation with $X_{\mathrm{Cu}}$ of the interband transition onset for disordered $\mathrm{Au}-\mathrm{Cu}$ alloys.

Such a behaviour is qualitatively similar to the one observed for Au-Ag alloys, which was satisfactorily reproduced by a theoretical treatment based on the coherent potential approximation [10].

3. Ordered alloys. - When annealing the asdeposited metastable disordered alloys (below the order-disorder transformation temperature), ordered phases can be obtained, which correspond to $\mathrm{AuCu}$ (I and II) for $0.35<X_{\mathrm{Cu}}<0.80$. Ordered phases corresponding to $\mathrm{Au}_{3} \mathrm{Cu}$ do exist but they could not be formed in sufficient quantities in our experiments.

The $\mathrm{AuCu}$ I superlattice is face centered tetragonal. The AuCu II superlattice is orthorhombic; it can easily be deduced from the $\mathrm{AuCu}$ I structure : $\mathrm{a} \mathrm{AuCu}$ 
II cell can be reproduced by putting side by side 10 tetragonal cells and by interchanging the positions of the $\mathrm{Cu}$ and the $\mathrm{Au}$ atoms after 5 cells (antiphase domains). The $\mathrm{AuCu}_{3}$ I superlattice is face centered cubic ; the $\mathrm{AuCu}_{3}$ II can be deduced from its structure in the same way as for the $\mathrm{AuCu}$ system.

It proved to be difficult to obtain completely ordered alloys, or alloys with maximum order in the case of out-of-stoichiometry alloys. It was then tried to deduce from the electron diffraction diagrams relative to each film a degree of order $S$ characterizing the amount of the different phases constituting this film. $S$ is equal to zero for a disordered alloy, and equal to 1 for a perfectly ordered alloy with the stoichiometric composition [11]. In the case of X-ray diffraction and for a powder diagram, $S^{2}$ is proportional to the ratio of the intensities of a superlattice ring and a normal ring. In the case of electron diffraction, this result, obtained in the framework of the kinematic theory, is only approximate since the dynamic theory must be used. It is however possible to determine relative degrees of order for films with the same thickness, by comparing the corresponding ratios of a superlattice ring and a normal $\operatorname{ring} I_{S} / I_{N}$. Since the films under investigation have a fiber structure with their [111] planes parallel to the substrate, it is necessary to consider rings corresponding to parallel reticular planes : usually $I_{110}$ over $I_{220}$.

$3.1 \mathrm{AuCu}_{3}$ Superlattice. - The $\mathrm{AuCu}_{3}$ II phase was obtained for $X_{\mathrm{Cu}}=0.70$ and both $\mathrm{AuCu}_{3}$ I and II phases for $X_{\mathrm{Cu}}=0.81$ (i. e. on either side of the stoichiometric composition $X_{\mathrm{Cu}}=0.75$ ). Figure 6

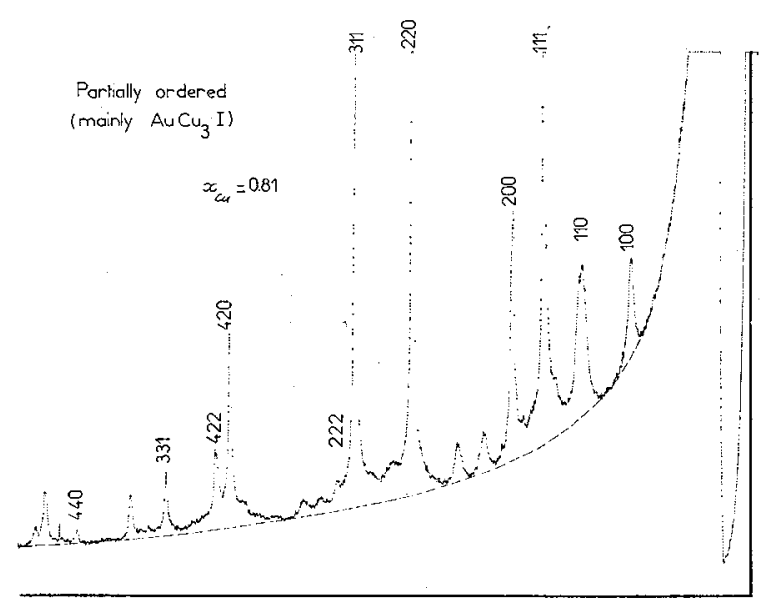

FIG. 6. - Microdensitometer analysis of an electron diffraction diagram of an alloy film with $X_{\mathrm{Cu}}=0.81$ which is partially ordered according to $\mathrm{AuCu}_{3} \mathrm{I}$.

shows the densitometer analysis of the diffraction diagram obtained for the last alloy in an almost completely ordered state, essentially according to $\mathrm{AuCu}_{3} \mathrm{I}$.
Figure 7 shows the curves of $\varepsilon_{2}$ versus energy in the interband transition range, obtained for an alloy with $X_{\mathrm{Cu}}=0.81$ in disordered state and in partially ordered states with different degrees of order. For small ordering, a wide bump centered at about $4 \mathrm{eV}$ appears in the $\varepsilon_{2}$ spectrum. When the degree of order increases, this bump becomes narrower and seems to move towards smaller energies ; it transforms into a well defined peak centered at $3.6 \mathrm{eV}$ for maximum order. The rest of the spectrum is not significantly modified. The peak found by Nilsson is centered at about $3.4 \mathrm{eV}$ for an alloy with $X_{\mathrm{Cu}}=0.75$ [12].

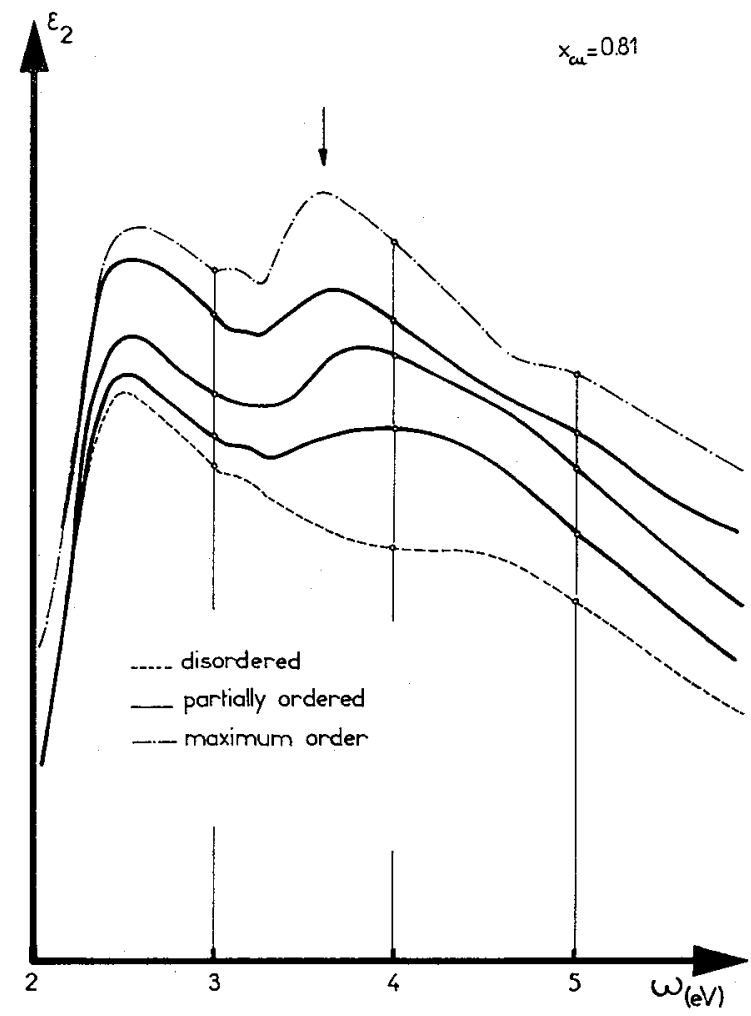

FIG. 7. - Imaginary part of the total dielectric constant $\varepsilon_{2}$ as a function of energy for an alloy film with $X_{\mathrm{Cu}}=0.81$, first disordered, then partially ordered according to $\mathrm{AuCu}_{3}$, with increasing degrees of order.

3.2 AuCu superlattice. - For a composition, $X_{\mathrm{Cu}}=0.54$, close to the stoichiometric composition, only the $\mathrm{AuCu} I$ phase is obtained. For a greater $\mathrm{Cu}$ concentration, $X_{\mathrm{Cu}}=0.59$, either the $\mathrm{AuCu}$ II phase, for which the (110) ring is splitted [13] as shown by figure 8 , or a mixture of the $\mathrm{AuCu}$ I and II phases, for which the (110) ring as well as its two satellites can be seen, are obtained, depending on the heat treatment.

Figure 9 shows the $\varepsilon_{2}$ spectrum for the ordered alloy with $X_{\mathrm{Cu}}=0.54$ : a supplementary peak centered at $3.75 \mathrm{eV}$ can clearly be seen. As this alloy was not studied optically in disordered phase it was tried to draw the corresponding spectrum by interpolating 


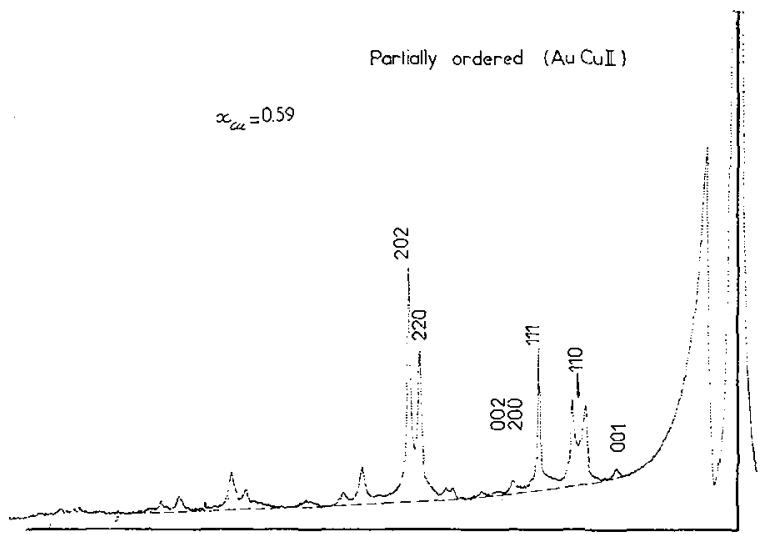

FIG. 8. - Microdensitometer analysis of an electron diffraction diagram of an alloy film $X_{\mathrm{Cu}}=0.59$, partially ordered according to $\mathrm{AuCu}$ II.

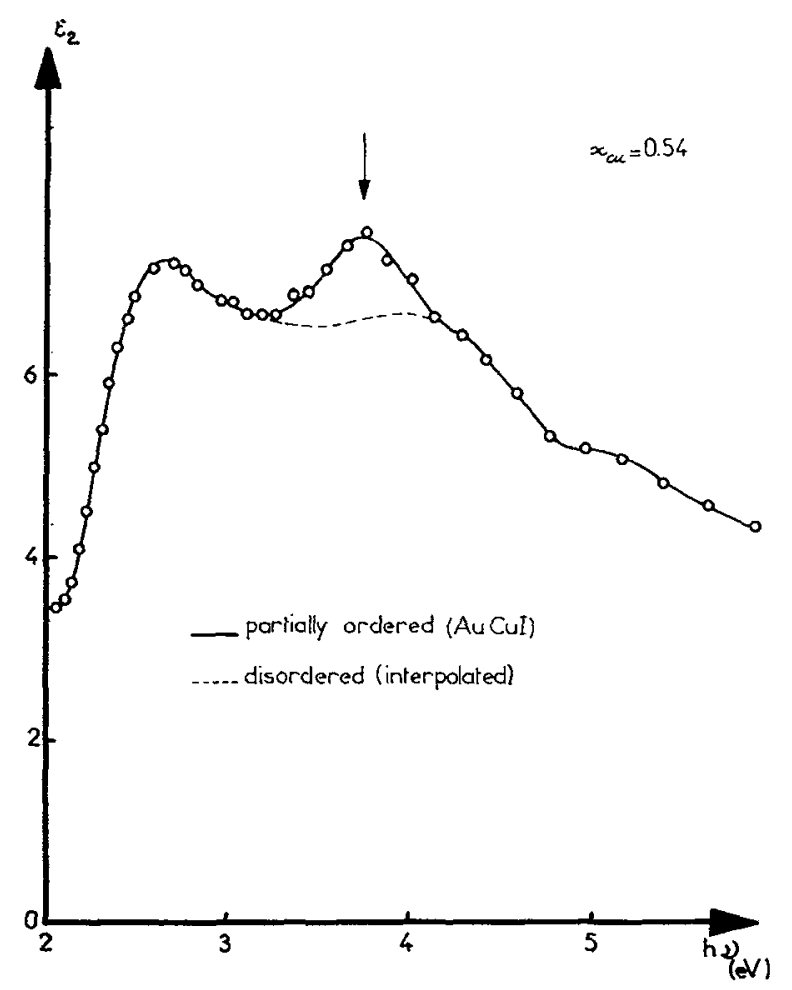

FIG. 9. - Imaginary part of the total dielectric constant $\varepsilon_{2}$ as a function of energy for an alloy film with $X_{\mathrm{Cu}}=0.54$, first disordered (interpolated curve), then partially ordered according to $\mathrm{AuCu} \mathrm{I}$.

the results for neighbouring compositions (dashed curve).

Figure 10 shows the $\varepsilon_{2}^{\text {inter }}$ curves for an alloy with $X_{\mathrm{Cu}}=0.40$ in disordered phase and in partially ordered phase according to AuCu II. The ordering effect does not appear so clearly in this case because of the presence for $X_{\mathrm{Cu}}<0.50$, of the strong Au-like peak around $4 \mathrm{eV}$. It can be seen however that this peak is shifted towards lower energies with ordering: it is centered at $3.75 \mathrm{eV}$ for this degree of order.

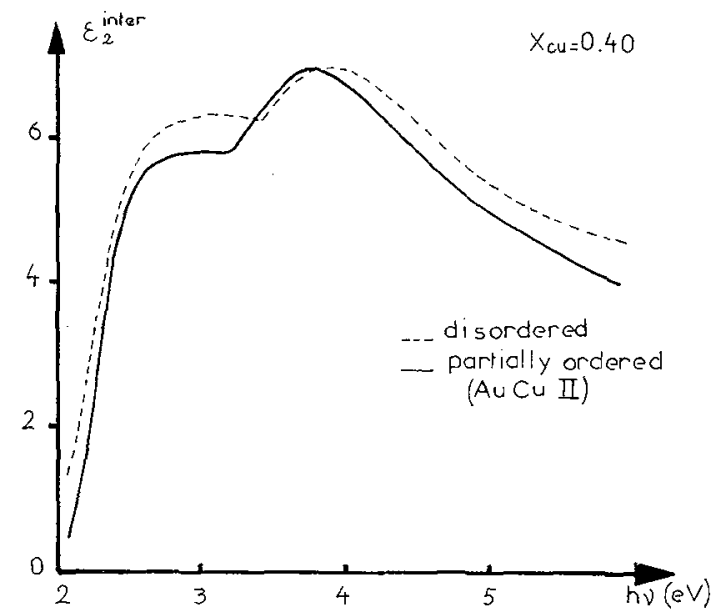

FIG. 10. - Contribution $\varepsilon_{2}^{\text {inter }}$ to the imaginary part of the dielectric constant $\varepsilon_{2}$ as a function of energy for an alloy film with $X_{\mathrm{Cu}}=0.40$, first disordered, then partially ordered according to $\mathrm{AuCu} \mathrm{II}$.

3. 3 ConClusion. - The influence of composition ordering on the optical properties of $\mathrm{Au}-\mathrm{Cu}$ alloys shows up in both contributions of intraband transition and of interband transitions.

As far as conduction electrons are concerned, it was found that ordering produces a decrease of the reciprocal optical relaxation time $\tau_{0}^{-1}$, which is however much smaller than the corresponding decrease of the electrical resistivity [7]. On the contrary, the optical mass seems not to be affected by ordering, at least within the limits of our experimental uncertainties.

As far as interband transitions are concerned, the presence of long-range order in the alloy introduces a supplementary absorption band in the $\varepsilon_{2}^{\text {inter }}$ spectrum. It was not yet possible to obtain accurate results for completely ordered alloys with the stoichiometric compositions corresponding to the superlattices $\mathrm{AuCu}_{3}$ or $\mathrm{AuCu}$. However, the location $\omega_{\mathrm{s}}$ of this peak can be given for alloys with slightly different compositions in which the degree of order is maximum or close to maximum: $\omega_{\mathrm{s}}=3.60 \mathrm{eV}$ for $\mathrm{AuCu}_{3}\left(X_{\mathrm{Cu}}=0.81\right)$, $\omega_{\mathrm{s}}=3.75 \mathrm{eV}$ for $\operatorname{AuCu}\left(X_{\mathrm{Cu}}=0.54\right)$. At the same time, the other features of the spectrum, especially the value of the interband transition onset and the shape of the absorption edge, are not significantly modified by ordering.

Acknowledgments. - The author would like to thank Professor F. Abeles for constant guidance and encouragement and Dr. M. L. Theye for many helpful discussions during the course of this work. The author is indebted to Dr. M. Gandais and Dr. R. Tixier who performed the electron microscopy studies and the electron microprobe analysis respectively. The research reported herein has been sponsored in part by the U.S. Department of the Army, through its European Research Office. 


\section{References}

[1] Philibert, J., Rivory, J., Bryckaert, D., Tixier, R., J. Phys. D 3 (1970) L 70.

[2] KIessig, H., Annln der Phys. 10 (1931) 5769.

Umrath, W., Z. Angew. Phys. 22 (1967) 406.

[3] Hansen, M., Constitution of binary alloys (Mc Grawhill, New York) 1958.

[4] Guinier, A. and Griffoul, R., Revue de Métallurgie 10 (1948) 387

[5] TheYe, M. L., Phys. Rev. B 2 (1970) 3060.

[6] Brouers, F., BrauWers, M. and RIVORY, J., to be published in J. Phys. F.
[7] Johansson, C. H. and Linde, J. O., Annln der Phys. 25 (1936) 1.

[8] Nilsson, P. O., Persson, A. and Hagström, S., Solid State Commun. 6 (1968) 297.

[9] Christensen, N. E. and Seraphin, B. O., Phys. Rev. B 4 (1971) 3321.

[10] Levin, K. and Ehrenreich, H., Phys. Rev. B 3 (1971) 4172.

[11] GuINIER, A., Théorie et technique de la radiocristallographie (Dunod, Paris) 1964.

[12] Nilsson, P. O. and Norris, C., Phys. Lett. 29 A (1969) 22. [13] Pianelli. A., C. R. Hebd. Séan. Acad. Sci. 248 (1959) 2475. 